\title{
Effects of mathematical game and instructional analogy as advance organizers on students' achievement in secondary school mathematics
}

\author{
Okigbo, D. E. ${ }^{1} \& \mathrm{Agu}^{2}$, N. N.
}

\begin{abstract}
The study investigated the effects of mathematical game and instructional analogy on students' achievement in junior secondary school mathematics. A total of 246 Junior Secondary Two (JS2) Mathematics students were involved in the study. A $3 \times 2$ factorial design was adopted in the research. From the findings, it was observed that: a. both game and analogy enhance achievement in mathematics, $b$. analogy was found to be more effective in facilitating students' achievement in mathematics than game, c. a nonsignificant difference existed between the achievement of male and female mathematics students taught with either game or analogy, and d. there was no significant interaction between the use/non-use of advance organizers and gender on mathematics students' achievement. It was recommended that teachers should be encouraged to adopt instructional analogy more than game in teaching number and numeration and algebraic processes in mathematics.
\end{abstract}

Keywords mathematical games, instructional analogy, mathematics achievement, advance organizers, gender differences in mathematics

\section{Introduction}

The compulsory nature of mathematics carries with it the assumption that the knowledge of the subject is essential for all members of the society. Mathematics competence is a critical determinant of the post-secondary education and career options available to young people (Okereke, 2006). Stressing on the importance of mathematics, Ukeje (1986) described the as the mirror of civilization in all the centuries of painstaking calculation and the most basic discipline for any person who would be truly educated in any science and in many other endeavours. Despite the importance placed on mathematics, it is very disappointing to note that students' performance in the subject at both internal and external examinations has remained consistently poor. Also, statistics show that mass failure in mathematics examination is real and the trend of students' performance has been on the decline (Betiku, 2002; Maduabum \& Odili 2006; WAEC, 2008; NECO, 2009).

Many variables had been identified by Betiku (2002) as responsible for the poor performance of students in mathematics. Such variables include governments, curriculum, examination bodies, teachers, students, home, and textbook. Apart from these

1 Okigbo, D. E. lectures at the Department of Science Education, Nnamdi Azikiwe University, P.M.B. 5025, Awka, Anambra State, Nigeria. E-mail: ebeleokigbo@yahoo.com

${ }^{2}$ Agu, N. N. is an Associate Professor in Educational Evaluation, Department of Educational Foundations, Nnamdi Azikiwe University, P.M.B. 5025, Awka, Anambra State, Nigeria. E-mail: ngozi_uj@yahoo.com 
Effects of mathematical game and instructional analogy as advance organizers on students' achievement in secondary school mathematics Okigbo, D. E. \& Agu, N. N.

variables, some specific variables have been identified by Udeinya \& Okabiah (1991) and Amazigo (2000) to include: poor primary school background in mathematics, lack of interest on the part of the students, lack of incentives for the teachers, incompetent teachers in primary schools, students not interested in hard work, perception that mathematics is difficult, large class syndrome, psychological fear of the subject, poor methods of teaching, and lack of qualified mathematics teachers, which results in teaching of the subject by unqualified, untrained and inexperienced auxiliary teachers.

The West African Examination Council's (WAEC) Chief Examiners annual reports for the WASSCE from 2005 to 2009 consistently suggested that students' performance in mathematics could be improved through meaningful and proper teaching (WAEC, 2005, 2006, 2007, 2008, 2009). According to the reports, teachers should help in reducing the abstractness of mathematics, and thence remove the students' apathy and fear of the subject. Thus it becomes pertinent to look for interventions that could be manipulated in order to find their effects on mathematics learning outcomes. This could address the problems of teaching and learning of mathematics in schools. Based on this, the researcher used mathematical games and analogies as advance organizers in teaching mathematics students two units of JS2 mathematics contents and compared their effects with teaching without advance organizer (using modified lecture method).

Mathematical games and instructional analogy are types of advance organizer learning strategies advocated by Ausubel (1962). Advance organizers according to Ausubel (1962) are introductory materials which bear some relationship to the new learning materials but often with greater depth inclusiveness and much more generalized. Onwioduokit \& Akinbobola (2005) had shown that physics students taught with pictorial and written advance organizers significantly achieved higher than those students taught without any advance organizer. Obodo (1997) described mathematical game as activity in form of puzzles, magic tricks, fallacies, paradoxes or any type of mathematics which provides amusement or curiosity and stimulates mathematical thinking, excitement and spirit of competition and co-operation. Games help to reduce the level of abstraction involved in teaching and learning a concept in mathematics, capture the learner's interest and provide environment for active participation of the students.

Harrison \& Treagust (1993) referred to instructional analogy as instances in instruction in which some less familiar domains or abstract concepts are made more understandable to the learner by making references to similar relations, objects or situations with which the learner is familiar. Researchers (Goswami, 1992; Bassok, 2001) across disciplines have shown that analogical reasoning may be central to learning of abstract concepts, procedures, novel mathematics and the ability to transfer representations across contexts. On the other hand, Nwagbo (1999) saw lecture (expository) method of teaching as a teacher-centered and student-peripheral teaching approach in which the teacher 'talks' about the subject and the students 'read' about it. However, modified lecture method used in this study involves more than 'talking' and 'reading' about mathematics because it allows some interactive between the teacher and the students in terms of asking and being asked questions on the topic of discussion (Okigbo, 2010).

Although mathematics is recognized as abstract subject that can easily be learnt by high achievers only, literature (Ezenwa, 1996; Nworgu, 2005) had shown that mathematics is more of boys' than girls' favourites. Strategies such as the use of games and analogies as 
advance organizers in teaching could help to enhance mathematics learning, appreciation and achievement. Though there are some differences between these two strategies, there are also some similarities. Both encourage students' active meaningful learning, working in teams, raising questions and exploring ideas and reasoning. Game activity is physicalcarrying out experiments, collecting data, etc, but analogy emphasizes conversation in the classroom, the activity is more intellectual than physical - more "minds-on" than "handson". Hence the researcher decided to use game and analogy as advance organizers in teaching some concepts in mathematics in order to observe their effect on students' achievement.

\section{Statement of the Problem}

Evidence of poor performance shown by researchers (Okereke 2006; WAEC, 2005-2009; NECO, 2009) indicates that the current methods of teaching mathematics may not be exciting to the students. This may lead to students' lack of understanding of the concepts, functionality and application of mathematics ideas. The WAEC Chief Examiners (2007, 2008 \& 2009) consistently reported that students dodge questions on number and numeration and algebra and when an attempt is made they show lack of understanding of the concepts in their workings. The question is 'could the use of game and analogy as advance organizers in teaching mathematics enhance achievement of mathematics students?'

\section{Purpose of the Study and research hypotheses}

The purpose of this study was to compare:

- mathematics achievement of students taught mathematics with games, analogies to those taught with modified lecture method (without advance organizers).

- achievement of male and female students taught mathematics with games and analogies.

The following hypotheses were formulated and tested.

1. There is no significant difference in the mathematics achievement of students taught with games and analogies and those taught with modified lecture method (without advance organizers).

2. There is no significant difference between the mathematics achievement of male and female students taught with (i) games, and (ii) analogies, as advance organizers

3. There is no significant interaction between gender and teaching methods as measured by the Mathematics Achievement Test (MAT).

\section{Method}

The design adopted for this research was $3 \times 2$ factorial design. This shows three (3) levels of experimental factors and two (2) levels of gender. The population was made up of 3900 Junior Secondary Two (JS2) mathematics students in the 50 co-educational schools in Awka (2496) and Ogidi (1404) Education Zones of Anambra state, Nigeria. A total of two hundred and forty-six (246) JS2 mathematics students took part in the research. Stratified and random sampling techniques were used to select six schools from the six Local Government Areas (one from each LGA). A random sampling technique through the use of balloting was carried out to select one intact class each from the six 
Effects of mathematical game and instructional analogy as advance organizers on students' achievement in secondary school mathematics Okigbo, D. E. \& Agu, N. N.

selected schools. Two intact classes were assigned to experimental group A (game group, $\mathrm{N}=84$ ), another two intact classes experimental group $\mathrm{B}$ (analogy group, $\mathrm{N}=95$ ) and the third group conventional group $\mathrm{C}$ (lecture group, $\mathrm{N}=67$ ) which were coded $01,02,03$ respectively.

The researcher structured the Mathematics Achievement Test (MAT) using junior WAEC past question papers (Nze, 2007). Also, the marking scheme for the MAT and three instructional tools (mathematical games, bridging analogy teaching plan, and lesson plan) were prepared.

Mathematics Achievement Test (MAT): This is a 20-item achievement test constructed based on the topics chosen for the study. The test consists of 20 objective questions adopted from Nze (2007). The choice and number of items picked in each unit depends on the time spent during the teaching period. The instrument was used as pre-test and after the treatment has been made, the same instrument was reshuffled and used as posttest.

Mathematical Game: Two games namely; Percentages, Fractions and Decimals and Algebraic games were used respectively for teaching number and numeration and algebraic processes. For Percentages, Fractions and Decimals game, researcher-made cards were used. The design of each card is similar and of the same colour. There are three different suits (18 cards per suit) of Fractions, Decimals and Percentage. Figure 1 presents the sample of the cards (Appendix A). For Algebraic game (Game 2), the teachers taught the students using table of magic instructions (Appendix B).

Instructional Analogy: Bridging analogy teaching plan was used for teaching instructional analogy group.

Lesson Plan: The lesson plan was used for teaching the conventional group $\mathrm{C}$ and the game group A.

To establish the validity of the games and bridging analogy teaching plan used as instructional tools, they were given to three lecturers in the Department of Mathematics of Nwafor Orizu College of Education, Nsugbe, Anambra State. From their observations and corrections one unit (Geometry and mensuration) was removed. These tools were trial tested using four classes from four schools that did not participate in the research. Also, the 30-item MAT was given to two experience secondary school mathematics teachers and the same three lecturers from Nsugbe for validation. At the end, only the items rated three (3) and above were chosen reducing it to 20 items. The reliability of MAT was established using Kuder Richardson formula 21 (kR-21). Forty students that did not take part in the study were tested with it and reliability was found to be 0.89 .

Experimental Procedure: The procedure used in conducting this study was presented in two stages.

\section{Stage One: Training programme for mathematics teachers}

The games and bridging analogy teaching plan were used for training the teachers in experimental groups A and B. The training lasted for six days involving three contacts each week. The activities for the six (6) days were as follows:

Day 1: Introduction of participants and the purpose of the training, discussion on teachers' experiences in the mathematics classroom, and presentation and analysis of WASSCE results and Chief Examiners reports on mathematics. 
Day 2: Discussions on: Advance organizer and examples, meaning of game and analogy, and games and analogies used as advance organizers.

Day 3: For group A, introduction of the two games to be used, building of cards, introduction of words to be used in algebraic game. For group B, introduction of six analogies to be used for teaching, contrasting analogy with the use of examples.

Day 4: Learning how to play the games for group A, and development and discussion of analogy teaching plan involving its integration in the actual lesson for group B.

Day 5: Continued discussion on the games and the lesson plan and bridging analogy teaching plan.

Day 6: Mini-teaching with games and analogy teaching plan and closing

\section{Stage Two: Teaching and evaluation of the students}

To account for possible pre-existing differences in overall ability between the groups, a pre-test was administered to them and the results were used as covariate measures. In order to control the teacher quality variable, both groups were trained by the researcher. The regular class teachers taught experimental group A with games and lesson plan and experimental group B with bridging analogy teaching plan. The control group $\mathrm{C}$ was taught by their own teachers without any advance organizer but with lesson plan. Both experimental and control groups were taught with the same two units (number and numeration, and algebraic processes) from JS2 mathematics syllabus (NERDC, 2005) for five weeks involving four contacts of 40 minutes each week. The post-test was administered to the two groups after the treatment.

The data collected were analyzed using Z-test and Analysis of Covariance (ANCOVA) using pre-test scores as covariates. The null hypotheses were all tested at 0.05 levels of significance.

\section{Results}

Differences in the mathematics achievement of students taught with games and analogies and those taught with modified lecture method

To test the hypothesis that "there is no significant difference in the achievement of mathematics students taught with games, analogies and those not taught with advance organizer but modified lecture method", pre-test scores were subjected to analyses of Covariance (ANCOVA) using pre-test scores as covariates. Table 1 shows the results of the statistical test on analysis of covariance (ANCOVA) of post-test scores of students taught with game, analogy, and modified lecture method. 
Effects of mathematical game and instructional analogy as advance organizers on students' achievement in secondary school mathematics Okigbo, D. E. \& Agu, N. N.

Table 1 One-way analysis of covariance (ANCOVA) of post-test scores of students taught with game, analogy, and modified lecture method

\begin{tabular}{|c|c|c|c|c|c|}
\hline Source & Sum of Squares & $\mathrm{df}$ & Mean Square & $\mathrm{F}$ & Sig. \\
\hline Corrected Model & $10259.57^{\mathrm{b}}$ & 7 & 1465.652 & 6.747 & .000 \\
\hline Intercept & 10316.30 & 1 & 10316.30 & 47.488 & .000 \\
\hline PREACHIE (covariate) & 3076.282 & 1 & 3076.282 & 14.161 & .000 \\
\hline PREINTER (covariate) & 4430.185 & 1 & 4430.185 & 20.393 & .000 \\
\hline METHOD & 6184.753 & 2 & 3092.376 & 14.235 & .000 \\
\hline Error & 51703.14 & 238 & 217.240 & & \\
\hline Total & 592575.0 & 246 & & & \\
\hline
\end{tabular}

From Table 1, a significant main effect was observed for teaching method with respect to post achievement $\mathrm{F}(2,238)=14.24, \mathrm{p}<0.001$. To specify the direction of the effect a Post Hoc Multiple Comparison of Post-test means (achievement) was carried out using Scheffe's test. This was presented in Table 2.

Table 2 Results of Scheffe's Post Hoc test for multiple comparison of the groups Achievement in Mathematics

\begin{tabular}{|c|c|c|c|c|c|c|c|}
\hline \multirow[b]{2}{*}{$\begin{array}{l}\text { Dependent } \\
\text { variable }\end{array}$} & \multirow[b]{2}{*}{$\begin{array}{l}\text { Teaching } \\
\text { method (I) }\end{array}$} & \multirow[b]{2}{*}{$\begin{array}{c}\text { Teaching } \\
\text { method }(\mathbf{J})\end{array}$} & \multirow[b]{2}{*}{$\begin{array}{c}\text { Mean } \\
\text { Difference } \\
(\mathrm{I}-\mathrm{J})\end{array}$} & \multirow[b]{2}{*}{$\begin{array}{l}\text { Std. } \\
\text { Error }\end{array}$} & \multirow[b]{2}{*}{ Sig. } & \multicolumn{2}{|c|}{$95 \%$ Confidence interval } \\
\hline & & & & & & $\begin{array}{l}\text { Lower } \\
\text { Bound }\end{array}$ & $\begin{array}{l}\text { Upper } \\
\text { Bound }\end{array}$ \\
\hline \multirow{6}{*}{ 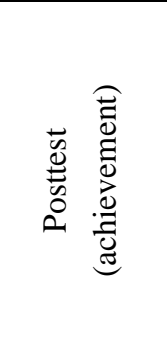 } & Game & Analogy & -5.0589 & 2.285 & .088 & -10.6857 & .5679 \\
\hline & & Lecture & $6.6827 *$ & 2.499 & .029 & .5288 & 12.8365 \\
\hline & Analogy & Game & 5.0589 & 2.285 & .088 & -5679 & 10.6857 \\
\hline & & Lecture & $11.7416^{*}$ & 2.434 & .000 & 5.7478 & 17.7353 \\
\hline & Lecture & Game & $-6.6827 *$ & 2.499 & .029 & -12.8365 & -5288 \\
\hline & & Analogy & $-11.7416^{*}$ & 2.434 & .000 & 17.7353 & -5.7478 \\
\hline
\end{tabular}

\footnotetext{
* The mean difference is significant at the 0.05 level
}

From table 2, the mean difference between game and analogy was -5.06 , between game and lecture was 6.68, and between analogy and lecture was 11.74. This implies that the use of analogy as advance organizer in teaching was the most effective in facilitating students' achievement in Mathematics. . 
Hypothesis Two $\left(\mathrm{Ho}_{2}\right)$

$\mathrm{Ho}_{2}$ (i): There is no significant difference between the achievement of male and female mathematics students taught with games. The analysis is as shown in Table 3.

Table 3 Z-test Comparison of post-test mean scores on achievement of male and female mathematics students taught with games

\begin{tabular}{lllllllll}
\hline Gender & N & Mean & SD & Df & $\begin{array}{l}\text { Std } \\
\text { error }\end{array}$ & Z-calculated & Z-critical & $\begin{array}{l}\text { Decision at } \\
\mathrm{P}<0.05\end{array}$ \\
\hline Male & 37 & 44.05 & 18.67 & 82 & 4.14 & 0.98 & 1.96 & $\begin{array}{l}\text { Not } \\
\text { significant }\end{array}$ \\
\hline
\end{tabular}

The analysis in Table 3 reveals that the calculated Z-value, 0.98, is less than the critical $\mathrm{Z}$-value, 1.96 , at $\mathrm{P}<0.05$. Therefore the null hypothesis of non-significant difference between the achievement of male and female mathematics students taught with games was retained.

$\mathrm{Ho}_{2}$ : There is no significant difference between the achievement of male and female mathematics students taught with games. The analysis is as shown on Table 4 .

Table 4: $\quad$ Z-test Comparison of post-test mean scores on achievement of male and female mathematics students taught with analogies

\begin{tabular}{|c|c|c|c|c|c|c|c|c|}
\hline Gender & $\mathrm{N}$ & Mean & SD & Df & $\begin{array}{l}\text { Std } \\
\text { error }\end{array}$ & Z-calculated & Z-critical & $\begin{array}{l}\text { Decision at } \\
\mathrm{P}<0.05\end{array}$ \\
\hline Male & 37 & 52.03 & 9.39 & & 7 & & & Not \\
\hline Female & 58 & 50.95 & 11.30 & & & & & significant \\
\hline
\end{tabular}

Analysis in Table 4 shows that the calculated Z-value, 0.50 , is less than the critical Zvalue, 1.96 , at $\mathrm{P}<0.05$. Therefore, the null hypothesis stating a non-significant difference between the achievement of male and female Mathematics students taught with analogies was retained.

Hypothesis Three $\left(\mathrm{Ho}_{3}\right)$

$\mathrm{Ho}_{3}$ : There is no significant interaction between gender and teaching methods as measured by the Mathematics Achievement Test (MAT).

The analysis is as shown on Table five. 
Effects of mathematical game and instructional analogy as advance organizers on students' achievement in secondary school mathematics Okigbo, D. E. \& Agu, N. N.

Table 5 Interaction Effect of Gender on the use and non-use of Advance organizers

\begin{tabular}{lcccccc}
\hline \multicolumn{1}{c}{ Source } & Dependent Variable & $\begin{array}{c}\text { Sum of } \\
\text { Squares }\end{array}$ & df & Square & F & P \\
\hline Method & Post-test (achievement) & 6184.75 & 2 & 3092.38 & 14.24 & 0.01 \\
Sex & Post-test (achievement) & 486.41 & 1 & 486.41 & 2.24 & 0.14 \\
Method X sex & Post-test (achievement) & 367.25 & 2 & 183.63 & 0.85 & 0.43 \\
Error & Post-test (achievement) & 57703.14 & 238 & 217.24 & & \\
Total & Post-test (achievement) & 61962.70 & 245 & & & \\
\hline
\end{tabular}

Table 5 reveals that there was no significant interaction between gender and teaching methods as measured by the mean achievement scores in MAT, F $(2,238)=0.85, \mathrm{P}<0.43$. Therefore, $\mathrm{Ho}_{3}$ was retained. This shows that the achievement of students in relation to the use and non-use of advance organizers was not influenced by gender of the students.

\section{Discussion of results}

The results of hypothesis one revealed that a significant difference was found to exist among the achievement of Mathematics students taught with games, analogies, and those taught with modified lecture. To specify the direction of the effect, a post hoc analysis as shown in Table 2 indicated that analogy was found to be most facilitating, followed by game and modified lecture was the least in enhancing students' achievement in Mathematics. This might have been due to the fact that the use of advance organizers (game and analogy) relates mathematics to real life. The result of this study agreed with the findings of Onwioduokit \& Akinbobola (2005) who assessed the efficacy of pictorial and written advance organizers in improving physics and prove them highly effective; Yilmaz, Eryilm \& Gebar (2006), who proved analogical application in mechanics classroom more effective than ordinary teaching method; and Anyamene \& Anyachebelu (2009) who reported that advance organizers had facilitative effect on achievement and retention in mathematics.

The results of hypothesis two showed that there was no significant difference between the achievement of male and female Mathematics students taught with game and analogy. The non-significant difference in the achievement of male and female Mathematics students is in line with the findings of Okonkwo (1997) and Okigbo \& Osuafor (2008) who reported that gender had non-significant effect on mathematics students' achievement when taught with tangram puzzle game and mathematics laboratory respectively.

The results of hypothesis three revealed a non-significant interaction between gender and use/non-use of advance organizers on students' achievement in mathematics. The study is in line with the finding of Iloputaife (2001) there was no significant interaction between instructional model and gender on students' achievement in physics.

\section{Conclusion}

On the basis of the findings in this study, the following conclusions were drawn:

1. Instructional analogy is more effective in enhancing students' achievement in mathematics than game.

2. Mathematics students taught with game and analogy performed better than those taught with modified lecture. 
3. There exists no significant difference between the achievement of male and female mathematics students taught with game and analogy.

4. There was no significant interaction between the use/non-use of advance organizers and gender on mathematics students' achievement.

\section{Recommendations}

Based on the results of the study, the following recommendations were made:

1. Mathematics teachers adopt the use of instructional activities such as game and analogy before, within and after a mathematics lesson.

2. To ensure that teachers of mathematics grasp the tenets of game and analogy, pre-service mathematics teachers should be trained on their use during their training process by the teacher educators.

3. Seminars and workshops should be organized for mathematics teachers, teacher educators, textbook writers and curriculum developers to appraise with the use of game and analogy.

\section{Appendix A Card design}

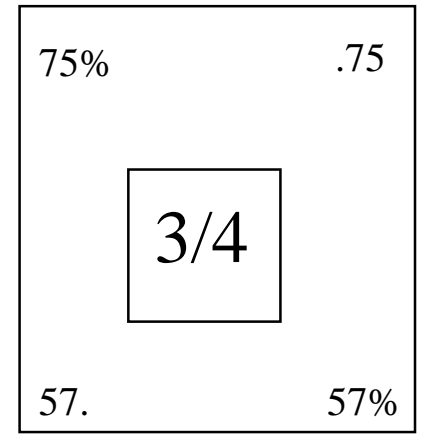

Figure 1
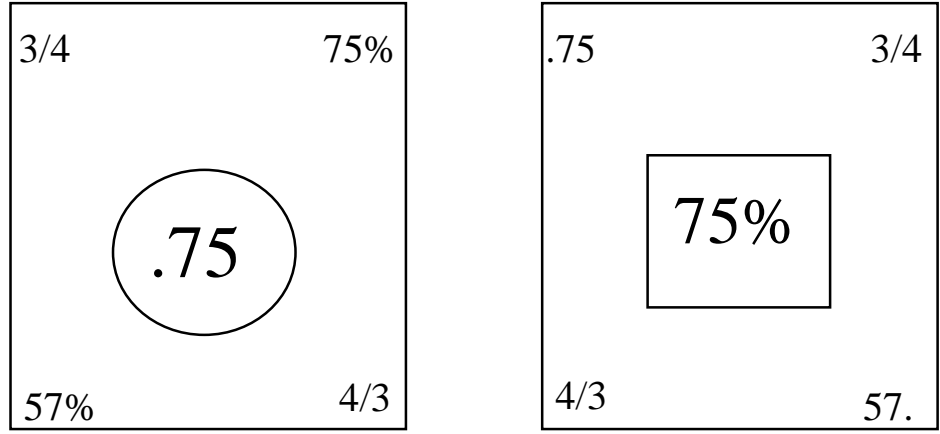

Sample of the cards from the deck 
Effects of mathematical game and instructional analogy as advance organizers on students' achievement in secondary school mathematics Okigbo, D. E. \& Agu, N. N.

Appendix B Magic instruction and algebraic response for finding House number and Real age

\begin{tabular}{|c|c|c|}
\hline $\mathbf{S} / \mathbf{N}$ & Instruction & Algebraic response \\
\hline 1. & Write down your house number & Let $n=$ house number \\
\hline 2 & Double it & $2 \times n=2 n$ \\
\hline 3 & Add 5 to the result & $2 n+5$ \\
\hline 4 & Multiply your result by 50 & $(2 n+5) \times 50=50(2 n+5)$ \\
\hline 5 & Add your real age to the result & $\begin{array}{l}\text { Let } a=\text { real age } \\
(100 n+250)+a\end{array}$ \\
\hline 6 & Add 365 to what you have so far & $\begin{array}{l}100 n+a+250+365 \\
100 n+a+615\end{array}$ \\
\hline 7 & Subtract 615 & $\begin{array}{l}100 n+a+615-615 \\
100 n+a\end{array}$ \\
\hline 8 & $\begin{array}{l}\text { Use slash }(/) \text { to separate the last } 2 \\
\text { digits in your final answer }\end{array}$ & $\begin{array}{l}\mathrm{n}=\text { house number } \\
\mathrm{a}=\text { real age }\end{array}$ \\
\hline
\end{tabular}

